\title{
Wear and Friction Behavior of Metal Impregnated Microporous Carbon Composites
}

Gultekin Goller

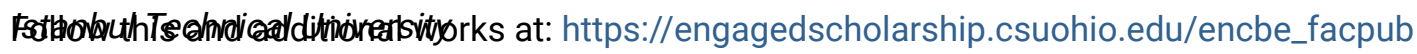

9. Proforf the Materials Science and Engineering Commons, and the Mechanics of Materials Commons Alpoviedblateriakss to this work benefit you? Let us know!

Sublisher's Statement

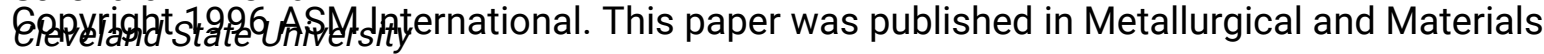
Transactions A: Physical Metallurgy and Materials Science, Vol. 27, Issue 11, pp. 3727-3738 and M. Singh available as an electronic reprint with the permission of ASM International. One print or NYMA NASA Lewis Group, Inc.

electronic copy may be made for personal use only. Systematic or multiple reproduction,

Aisfreksirtion to multiple locations via electronic or other means, duplications of any material in

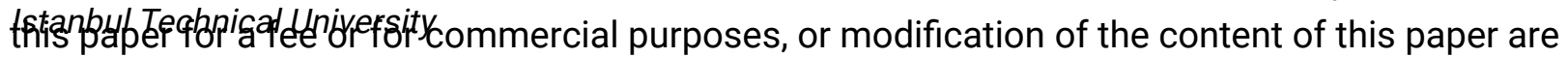
prohibited.

Available on publisher's site at: http://www.springerlink.com/content/q6782u1424534562/.

\section{Original Citation}

Goller, G., Koty, D.P., Tewari, S.N., Singh, M., \& Tekin, A. (1996). Wear and Friction Behavior of Metal Impregnated Microporous Carbon Composites. Metallurgical and Materials Transactions A: Physical Metallurgy and Materials Science 27, 3727-3738.

Repository Citation

Goller, Gultekin; Koty, D. P.; Tewari, Surendra N.; Singh, M.; and Tekin, A., "Wear and Friction Behavior of Metal Impregnated Microporous Carbon Composites" (1996). Chemical \& Biomedical Engineering Faculty Publications. 12.

https://engagedscholarship.csuohio.edu/encbe_facpub/12

This Article is brought to you for free and open access by the Chemical \& Biomedical Engineering Department at EngagedScholarship@CSU. It has been accepted for inclusion in Chemical \& Biomedical Engineering Faculty Publications by an authorized administrator of EngagedScholarship@CSU. For more information, please contact library.es@csuohio.edu. 


\title{
Wear and friction behavior of pressure infiltration cast copper-carbon composites
}

\author{
G. Göller ${ }^{1}$, D. P. Koty ${ }^{2}$, S. N. Tewari ${ }^{2}$, M. Singh ${ }^{3}$ and A. Tekin ${ }^{1}$ \\ ${ }^{1}$ Istanbul Technical University, Faculty of Metallurgical Engineering, 80626 Maslak, Istanbul, Turkey; ${ }^{2}$ Cleveland State University, Chemical Engineering \\ Department, Cleveland, Ohio, 44115; ${ }^{3}$ NYMA-NASA Lewis Group, Cleveland, Ohio, 44115, USA
}

Copper matrix-carbon composites are attractive for wear applications, such as, sliding electrical contacts, bearings and bushings [1]. Mostly, graphitic carbon, has been used for these composites because its addition (graphite particle volume fraction $>0.2$ ) [2] reduces the coefficient of friction and increases the wear resistance, as compared with the matrix. Easy glide of the basal planes under ambient conditions is responsible for the lubricity and antiseizure characteristics of graphite. Glassy (amorphous) carbon, on the other hand, is much harder, approximate knoop hardness of $1300 \mathrm{~kg} / \mathrm{mm}^{2}$ [3]. One would therefore expect very different wear and friction behavior of the copper alloy composites based on the amorphous versus graphitic carbon. We have recently reported the room temperature wear and friction behavior of $\mathrm{Cu}-6 \mathrm{Si}$ $0.9 \mathrm{Cr}$ alloy-carbon composites, containing varying fractions of the amorphous and graphitic carbon, against cast iron plate [4]. In this paper we report the load dependence of the room temperature wear and friction behavior of these composites wearing against their own plates. Microporous carbon preforms $[5,6]$ were used instead of the conventionally used carbon particulates [2], because their melt infiltration was expected to result in a fine and uniform distribution of the 2 phases, metallic matrix and carbon (amorphous and graphitic). Such a fine distribution is desirable for mechanical properties and wear resistance.

\section{Experimental procedure}

\section{Preform fabrication}

The microporous carbon preforms were made from a mixture of furfuryl alcohol resin, diethylene and triethylene glycol, and p-toluene sulphonic acid [5, 6]. The mixture was polymerized to form a porous solid polymer which is heated up to $973 \mathrm{~K}$ to yield porous amorphous carbon preform. Graphite particulates (-440 mesh) were mixed into the above liquid mixture to yield varying proportions of amorphous versus graphitic carbon in the porous preforms. Mercury porosimetry was used to characterize the pore size distribution of the preform.

\section{Melt infiltration}

The Cu-6Si-0.9Cr (by weight \%) alloy ingots were prepared by induction melting the charge in an alumina crucible under a flowing UHP argon atmosphere. This alloy has a liquidus of $1129 \mathrm{~K}$. The alloy was remelted in a pressure infiltration casting facility and was pushed upwards into cylindrical microporous preforms $(0.6 \mathrm{~cm}$ diameter, $10 \mathrm{~cm}$ long) 

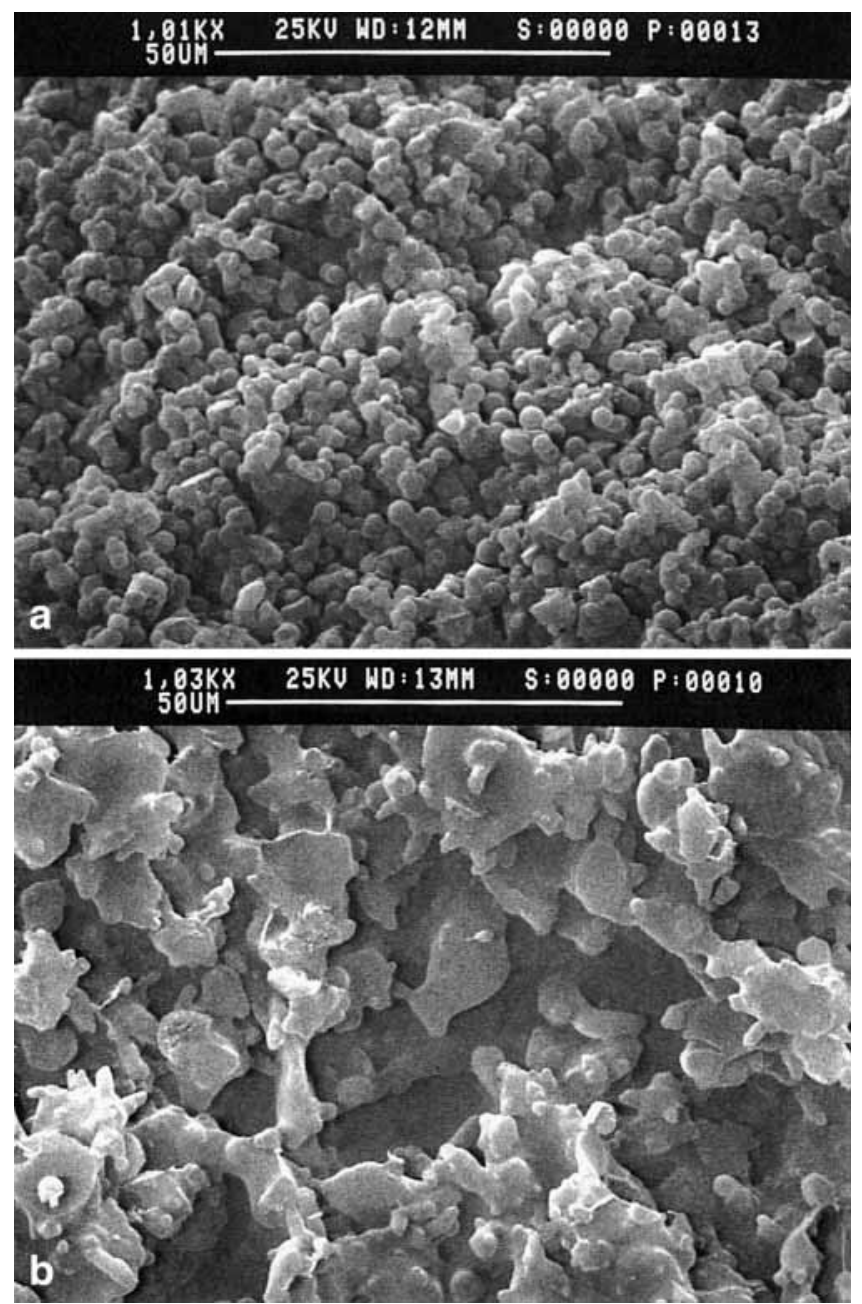

Fig. 1. Typical scanning electron microscopy image of microporous carbon preforms. (a) " $A$ ", 100\% amorphous carbon. (b) " $B$ ", $40 \%$ graphite and $60 \%$ amorphous carbon.

kept in an alumina tube by the help of 500 psi argon pressure. The pressure infiltration casting facility provided independent control of the melt and preform temperatures in order to achieve successful infiltration.

\section{Wear and friction behavior}

Wear and friction experiments were carried out in a pin-on-plate reciprocating wear tester [7] under ambient conditions at room temperature. Composite pins $(2.2 \mathrm{~cm}$ long and $0.6 \mathrm{~cm}$ in diameter) were tested against composite plates (wear track length $=2 \mathrm{~cm}$ ). The load, ranging from 12 to $30 \mathrm{Kg}$ (19 to $49 \mathrm{MPa}$ ) was applied on the composite pin, rubbing against the reciprocating plate (linear speed $20 \mathrm{~cm} \mathrm{~s}^{-1}$ ). The friction force and pin displacements, measured by transducers, were recorded by the help of a Hewlett Packard data acquisition unit. Because of the reciprocating motion involved, the plate and the pin came to rest at the end of each cycle, and the rod impacting on the friction force transducer vibrated vigorously. Therefore, a triggering arrangement was used to stop the data acquisition near the end of the cycle, to prevent collecting these erratic data. The time for each run, 90 min, and all other variables were kept constant.

\section{Results}

\section{Microstructure}

Preform. Fig. 1 shows typical microstructures of the 2 types of microporous carbon preforms examined in this study. One contains only amorphous carbon (Fig. 1a), and the other contains 40 wt. $\%$ graphite and 60 wt \% amorphous carbon (Fig. 1b). The carbon struts and the interconnected continuous porosity can be clearly seen in these scanning electron micrographs. Addition of graphite particles resulted in significant increase in the pore sizes, for otherwise identical processing conditions. The pore size distributions, obtained by mercury porosimetry, are presented in Fig. 2. The presence of graphite results in a changed pore size distribution. For the amorphous carbon preform,
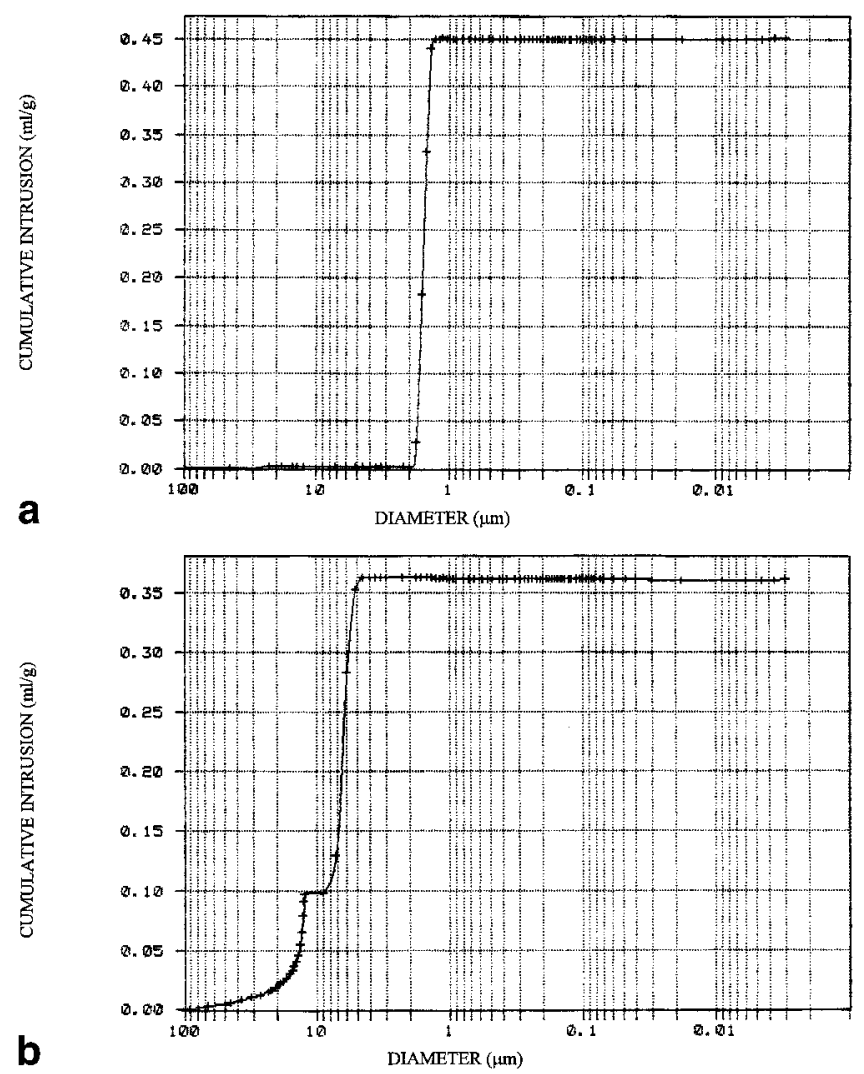

Fig. 2. Pore size distributions, obtained by mercury porosimetry. (a) " $A$ ", 100\% amorphous carbon. (b) " $B$ ", $40 \%$ graphite and $60 \%$ amorphous carbon. 
the skeletal density measured by mercury porosimetry, $1.48 \mathrm{gcm}^{-3}$, is in close agreement with the density of glassy carbon, $1.5 \mathrm{gcm}^{-3}$, indicating the continuity of pores (in the presence of isolated pores, the skeletal density would appear to be less than the true density of the amorphous carbon). Addition of graphite has resulted in increased pore sizes, from $1.6 \mu \mathrm{m}$ to 6.63 $\mu \mathrm{m}$.

Composite. Typical microstructures of the 2 infiltration cast composites are presented in Fig. 3. In these micrographs, the light regions are the copper alloy matrix and the gray regions are the amorphous carbon. Both the uninfiltrated pores and graphite particles (typically marked by arrows) appear dark. Both constituents in the microstructure, the carbon and the metallic phase, are much finer in the amorphous carbon composite (Fig. 3a) as compared with that containing $40 \%$ graphitic carbon (Fig. $3 \mathrm{~b}$ ). There was very
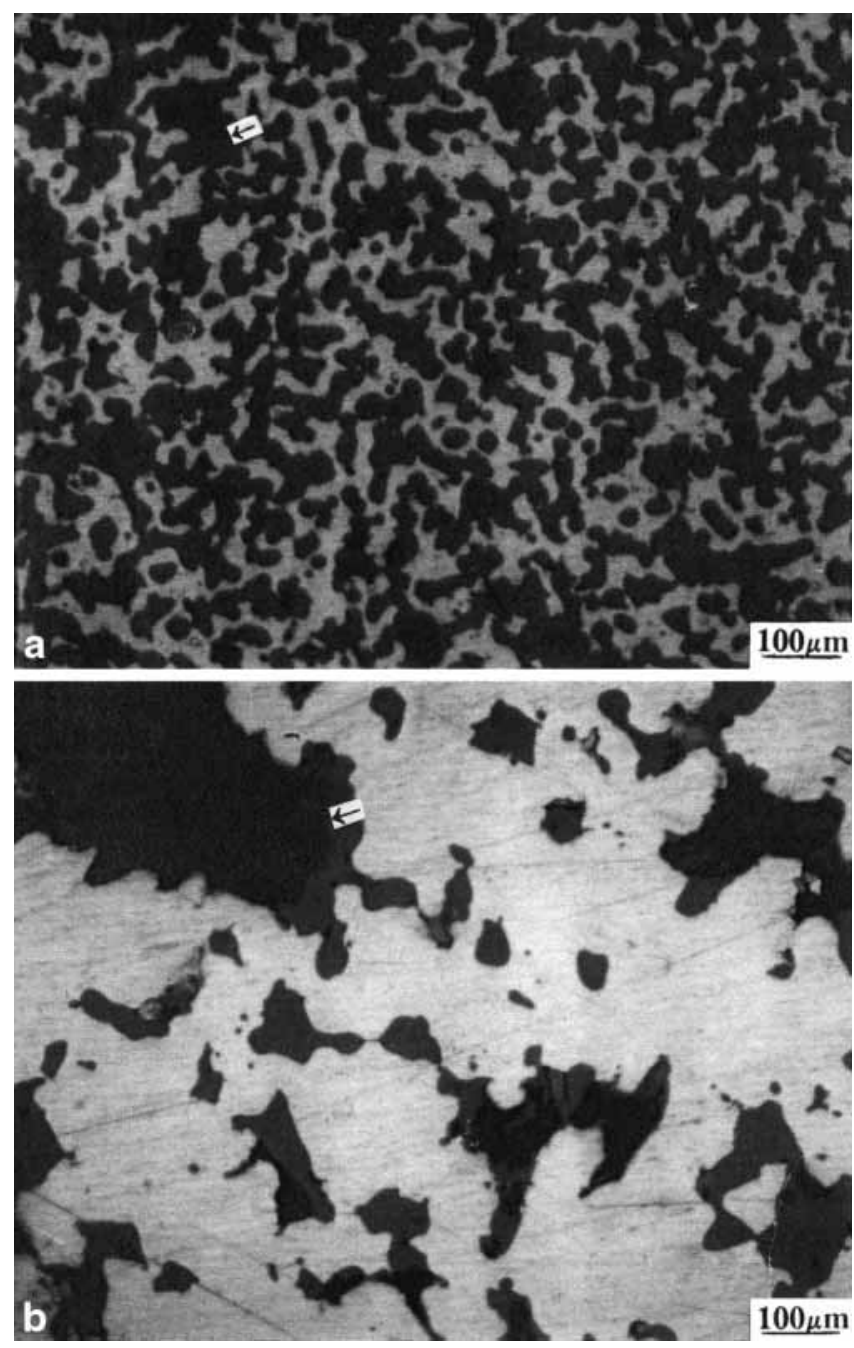

Fig. 3. Typical microstructures of the infiltration cast composites. (a) " $A$ " composite based on amorphous carbon preform. (b) " $B$ " composite based on $40 \%$ graphite $+60 \%$ amorphous carbon preform. little porosity observed in the amorphous carbon composite. In the other composite, agglomeration of the graphite particles was not observed, but numerous uninfiltrated pores (typically marked by an arrow in Fig. 3b) were seen. Amorphous carbon appeared to nucleate on the preexisting graphite particles, and produce isolated pores in their vicinity which did not get infiltrated by the copper alloy melt.

\section{Wear and friction}

The initial transients in the coefficient of friction versus sliding distance data are presented in Fig. 4 for several normal stress values, ranging from 19 to 49 $\mathrm{MPa}$. Fig. 4a represents the composite " $\mathrm{A}$ ", containing $100 \%$ wt amorphous carbon, pin wearing against itself, and Fig. $4 \mathrm{~b}$ represents composite " $\mathrm{B}$ ", containing $40 \%$ graphite and $60 \%$ amorphous carbon, wearing against itself. For the " $\mathrm{A}$ " composite, the coefficients of friction showed an initial decrease to about 0.13 before they increased to their steady-state values corresponding to the normal stress. With increasing normal stress on the pin, the rates of initial drop in the coefficient of friction and that of its subsequent rise were observed to increase (Fig. 4a). The time-period corresponding to the minimum in the coefficient of friction was observed to decrease with the increasing normal stress. The " $\mathrm{B}$ " composite containing $40 \%$ graphite did not show this initial decrease in the coefficient of friction (Fig. 4b). Here, the friction coefficients were observed to start from a low value and slowly increase to their steady-state values. For both the composites, the friction coefficients were observed to fluctuate. The extent of their fluctuation is typically shown in Fig. 5 during their steady-state stage. Increasing normal stress on the pin not only results in higher coefficients of friction, but also increases the extent of fluctuation. The extent of fluctuation, as indicated by one standard deviation, is about 0.003 for both type " $\mathrm{A}$ " and " $\mathrm{B}$ " composites at $17 \mathrm{MPa}$. However, at $49 \mathrm{MPa}$, the fluctuations are about 0.005 and 0.016 for " $\mathrm{A}$ " and " $\mathrm{B}$ ", respectively. It is interesting to note that at higher normal stress, despite the presence of large volume fraction of graphitic carbon, the extent of fluctuation in the " $\mathrm{B}$ " composite is significantly larger than that in " $\mathrm{A}$ ". For both the composites, the steady-state values of the coefficient of friction were observed to increase with the increasing normal stress (Fig. 6). For the " $\mathrm{A}$ " composite, it increased from about 0.17 at $10 \mathrm{MPa}$ to about 0.23 at $49 \mathrm{MPa}$, whereas, for the " $\mathrm{B}$ " composite, it increased from about 0.1 at $10 \mathrm{MPa}$ to about 0.2 at $49 \mathrm{MPa}$. Friction coefficient values are slightly less in the presence of graphitic carbon. The wear rates of both the com- 

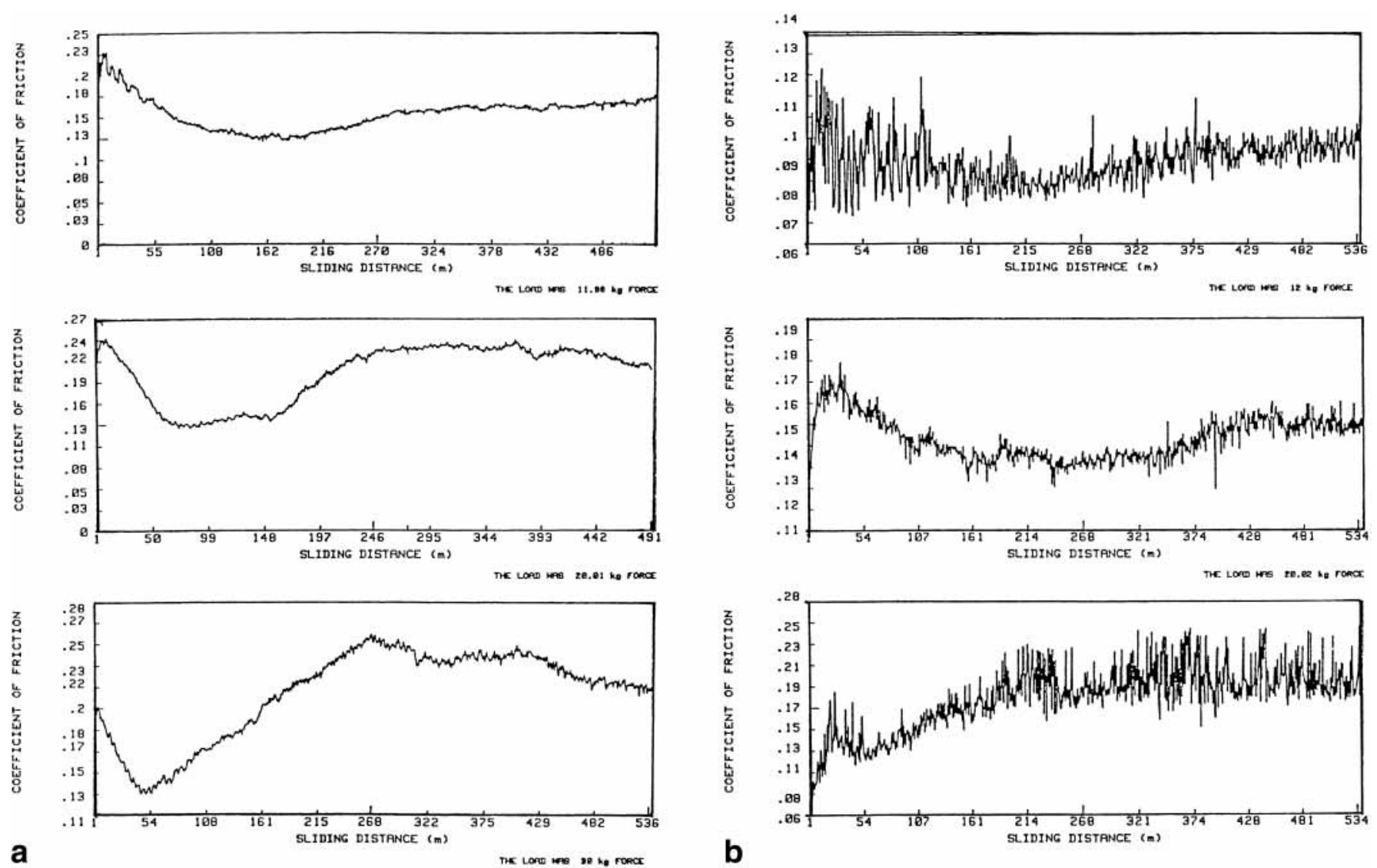

Fig. 4. Initial transients in the coefficient of friction versus sliding distance (room temperature, linear speed $=20 \mathrm{~ms}^{-1}$ ) as a function of the normal stress on the pin. (a) Coefficient of friction for " $A$ " composite pin on " $A$ " composite plate. (b) Coefficient of friction for " $B$ " composite pin on " $B$ " composite plate.

posites were observed to be nearly identical for the experimental conditions examined in this study (Fig. 7 ). Their wear rate was approximately $6.94 \times 10^{-6}$ $\mathrm{mmm}^{-1} \mathrm{MPa}^{-1}$.

Metallography of the wear surface. At low stress (up to about $19 \mathrm{MPa}$ ), the tribosurface of the " $\mathrm{A}$ " composite pin was almost covered by a thin, translucent, carbon film. Further breakage of this film was observed at the higher normal stress on the pin. However, most of the pin surface area remained covered with this film, as shown in Fig. 8a at $40 \mathrm{MPa}$. The finely distributed, 2phase, microstructure of the composite is clearly visible through this film. Non-conducting (copper oxide) debris particles, accumulating at the edges of the film where it fractured, are responsible for the sharp bright contrast (typical region marked by an arrow). The surface of the wear track was also observed to be mostly covered with amorphous carbon, as shown in Fig. 8b. It shows a cross section through the wear track of the " $\mathrm{A}$ " composite plate. Notice the gray amorphous carbon particles at the surface, almost covering the entire surface. With increased normal stress on the pin (e.g., at $49 \mathrm{MPa}$ ), breakage of this film resulted in more of the bright metallic constituents being directly exposed to the pin surface. X-ray diffraction analysis of the wear debris showed it to be mostly amorphous carbon and copper oxide.

Fig. $8 c$, shows the typical appearance of the pin surface after testing at $49 \mathrm{MPa}$ for " $\mathrm{B}$ " composite. There is extensive plastic deformation, grooving and delamination in the metallic matrix portions of the composite microstructure. The matrix has flowed over the carbon-containing regions, and the debris has accumulated in the grooves from where material was pulled off due to the adhesion and delamination. The cross section through the wear groove in the " $\mathrm{B}$ " plate also shows evidence of adhesion and delamination (Fig. 8d) on the plate surface.

\section{Discussion}

The tribological behavior of these composites is different, mainly because of the size and distribution of their microstructural constituents. The " $\mathrm{A}$ " composite, 

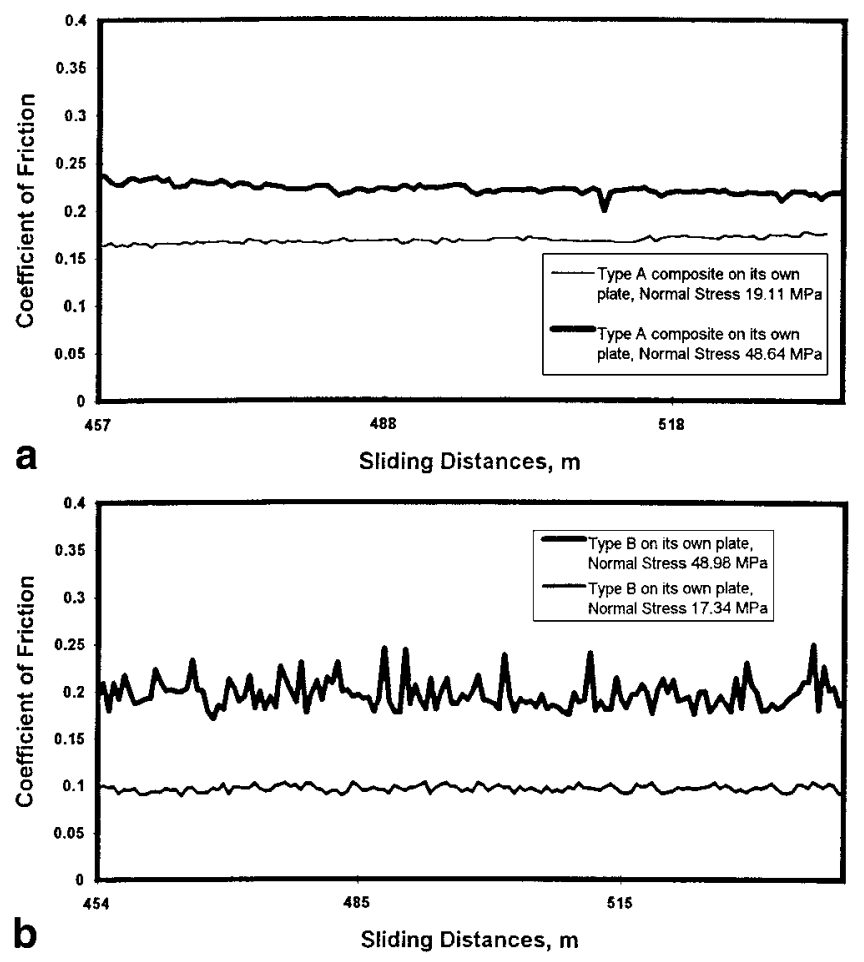

Fig. 5. Extent of fluctuation in the steady-state coefficient of friction as a function of normal stress on the pin. (a) " $A$ " composite pin on " $A$ " composite plate. (b) " $B$ " composite pin on " $B$ " composite plate.

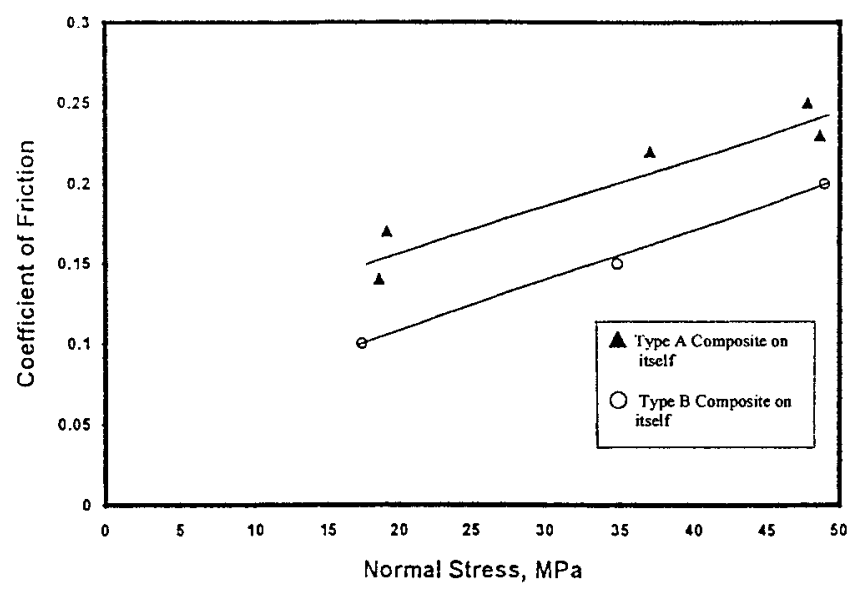

Fig. 6. Dependence of the steady-state coefficient of friction on the applied normal stress during wear of " $A$ " and " $B$ " composite pins on their own plates.

based on $100 \%$ amorphous carbon has very fine carbon struts (about $30 \mu \mathrm{m}$ ) and metallic phase (about 10 $\mu \mathrm{m})$. Such a distribution encourages the formation of amorphous carbon coating on the wear surface, over which the 2 mating surfaces glide and abrade each other. This is specially true at low to intermediate loads on the pin. With the increasing load, some of the metallic constituents on the pin surface come in

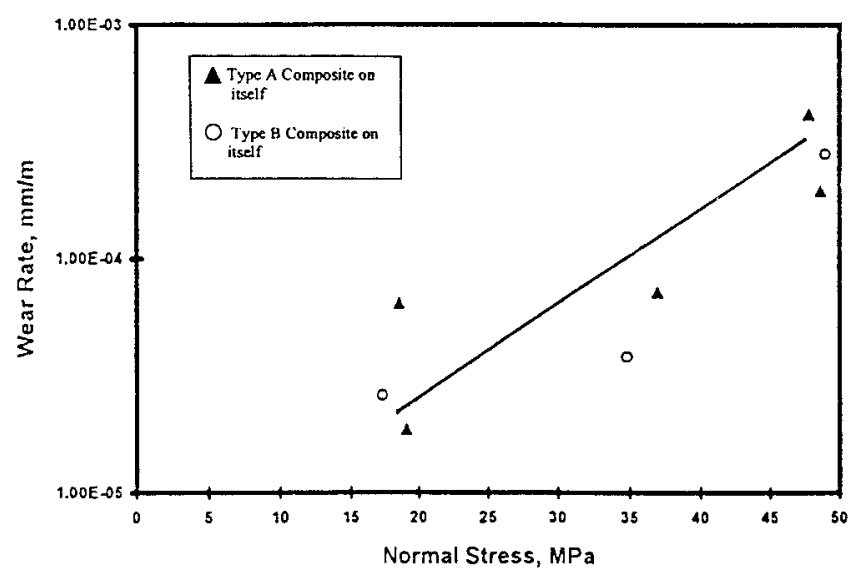

Fig. 7. Dependence of the wear rates on the applied normal stress during wear of " $A$ " and " $B$ " composite pins on their own plates.

direct contact with those in the plate surface, leading to their adhesion, which is followed by delamination. The process of adhesion and delamination gives rise to increasing fluctuation in the friction coefficient. However, the fine microstructure of the " $\mathrm{A}$ " composite does not allow a large extent of adhesive wear. In the type " $\mathrm{B}$ " composite, based on the $40 \%$ graphite and $60 \%$ amorphous carbon, the constituents are much larger (metallic constituents about $50 \mu \mathrm{m}$, amorphous carbon about $37 \mu \mathrm{m}$, and graphite about 57 $\mu \mathrm{m})$. At the very low loads, the graphite and amorphous carbon, pulled out from the pin and plate on to the tribo-surface, lead to a continuous film formation and an abrasive wear with low coefficient of friction (about 0.1). However, this microstructure is not conducive to maintaining a continuous carbon layer over the metallic constituents at higher loads, where the metallic constituents in the pin and the plate come in direct contact with each other leading to their repeated adhesion and delamination. This results in the experimentally-observed extensive fluctuation in the coefficient of friction (Fig. 5b).

The different initial transients of the " $\mathrm{A}$ " and " $\mathrm{B}$ " composites in their coefficient of friction versus sliding distance are also due to this competition between the formation of the carbon film on the wear surface and the adhesion between the metallic constituents. Expulsion of carbon (or graphite) on to the tribosurface is much easier for the "B" composite, as compared to the " $\mathrm{A}$ " composite. The " $\mathrm{B}$ " composite, therefore, initially shows a very low coefficient of friction (Fig. $4 b)$, which almost immediately begins to increase as more and more adhesion is achieved among the metallic constituents. An equilibrium between the material transfer on to the tribosurface by repeated adhesion and delamination, and wear debris removal, 

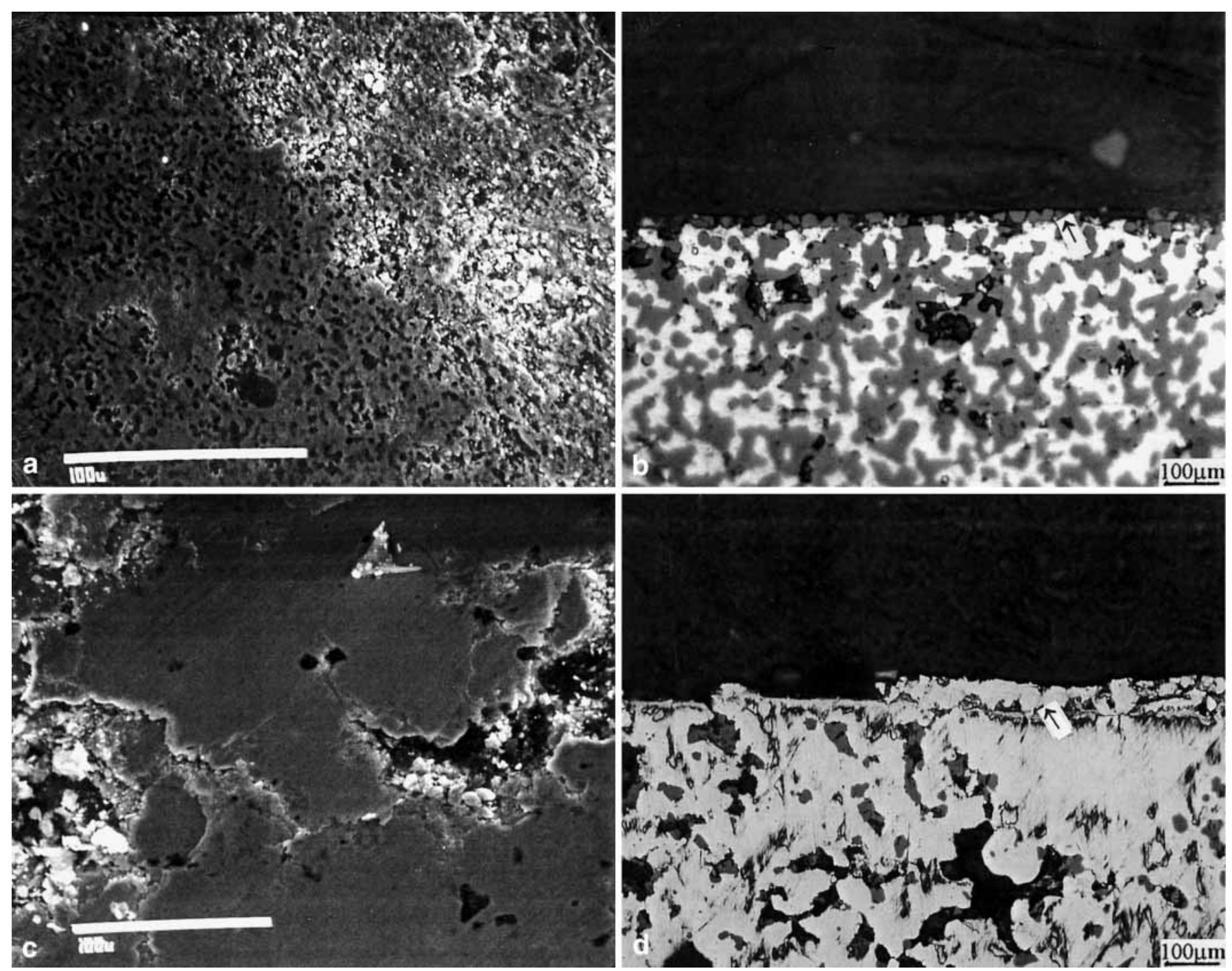

Fig. 8. Microstructure of the tribo-surfaces after wear. (a) Surface of the "A" pin after wear at $40 \mathrm{MPa}$. (b) Cross section through the wear grove in " $A$ " plate after wear at $40 \mathrm{MPa}$. (c) Surface of the "B" pin after wear at $49 \mathrm{MPa}$. (d) Cross section through the wear grove in "B" pin after wear at 49 Mpa.

ultimately leads to the steady-state coefficients. For the " $\mathrm{A}$ " composite, the initial decrease is obtained as more and more amorphous carbon is pulled out onto the tribosurface leading to the increasing formation of the continuous carbon film. With increasing time, however, some of the metallic constituents are also pulled out onto the tribosurface. The friction coefficient then begins to increase, finally reaching its steady-state value when dynamic equilibrium is achieved between the material transfer onto the tribosurface by abrasive wear and removal of the wear debris. The initial transfer of the amorphous carbon onto the tribosurface, and the subsequent erosion of the metallic constituents, are both promoted by the higher loads, leading to the steeper slopes during the initial transients at $49 \mathrm{MPa}$ as compared with those at $17 \mathrm{MPa}$ (Fig. 4a).

\section{Conclusions}

The following conclusions can be drawn from this research on pressure infiltration cast $\mathrm{Cu}-\mathrm{C}$ based metal matrix ceramic composites. The thin carbon film formed on the tribo-surface of graphite containing amorphous carbon-based metal matrix composites reduced the coefficent of friction and wear, especially at low loads on pin. Adhesive type of wear on the tribosurface promoted the wear and friction at high loads. Graphite addition would be beneficial at high loads only if the fine pore size distribution of the amor- 
phous carbon can also be retained in the preforms containing graphite particles.

\section{Acknowledgements}

Appreciation is expressed to J. Smith, C. Palda and B. Hanyaloglu for providing assistance, and to NASALewis Research Center and UNIDO for partially supporting this research. We are grateful to Professor S. Nourbaksh (New York Polytechnick Institute) for sharing the design of his pressure caster with us.

\section{References}

1. Zuben CZ. J Metals 1992: 44: 15.

2. Rohatgi PK, Ray S, Liu Y. International Matls Rev 1992: 37: 129-149.

3. Burton RA, Burton RG. Trans ASME 1990: 112: 68-72.

4. Göller G, Koty DP, Singh M, Tewari SN, Tekin A. Metallurgical \& Materials Transactions 1996: 27A: 3727-3737.

5. Hucke EE. US Patent 1975: 3459421.

6. Singh M, Behrendt DR. NASA-TM-105860, Lewis Research Center 1992

7. Mortimer D, Nicholas M. J Mater Sci 1970: 5: 149-155. 